\title{
HIV Drug Resistance Patterns at the Epicentre of the HIV-1 Epidemic in Kwazulu-Natal, South Africa 2003-2013
}

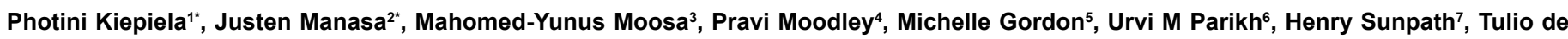
Oliveira $^{2}$ and Gita Ramjee ${ }^{1}$

${ }^{1}$ HIV Prevention Research Unit, Medical Research Council, 123 Jan Hofmeyr Road, Westville 3630, Durban, South Africa

${ }^{2}$ Africa Centre for Health and Population Studies, College of Health Sciences, University of KwaZulu-Natal, Durban, South Africa

${ }^{3}$ Department of Infectious Diseases, School of Clinical Medicine, College of Health Sciences, University of KwaZulu-Natal, Durban, South Africa

${ }^{4}$ Department of Virology, National Health Laboratory Service / University of KwaZulu-Natal, Durban, South Africa

${ }^{5}$ HIV Pathogenesis Programme, College of Health Sciences, University of KwaZulu-Natal, Durban, South Africa

${ }^{6}$ Department of Infectious Diseases, University of Pittsburgh School of Medicine, Pittsburgh, PA, USA

${ }^{7}$ Sinikithemba, McCord Hospital, Durban, South Africa

${ }^{*}$ Equal contribution, joint first authors

\begin{abstract}
South Africa has the highest number of individuals with HIV-1 infection worldwide with the epicentre of the epidemic in the province of KwaZulu-Natal (KZN). Currently South Africa has the largest antiretroviral treatment (ART) programme with KZN and Gauteng provinces accounting for $56 \%$ of all patients on ART. In order to understand transmission dynamics and temporal trends in drug resistance, we performed a comprehensive literature review of primary and acquired drug resistance in adults and children in KZN over a ten year period, 2003-2013.

Transmitted drug resistance (TDR) to non-nucleoside reverse transcriptase inhibitors (NNRTIs) in adults is increasing to moderate levels $(5-15 \%)$. Acquired drug resistance to first line drug regimens in adults was associated with at least one mutation to nucleoside reverse transcriptase inhibitors (NRTI) or NNRTIs or both, with M184V and $\mathrm{K} 103 \mathrm{~N}$ the most common mutations. Prevalence of thymidine analogues (TAMs) was low to moderate. There was no published data on acquired drug resistance to second line agents. Children failing first line drug regimens harboured drug resistance mutations to NRTI (M184V and TAMs), NNRTI (V106M and K103N) and protease inhibitors (PIs) (V82A).

Concerns have been raised about the high levels of the K65R mutation associated with tenofovir regimens in adults and children. Continued vigilance is needed for ART failure in both adults and children, so as not to compromise second line treatment options. Drug resistance genotyping is now cost effective and should be considered for inclusion in regional surveillance studies and during routine care.
\end{abstract}

Keywords: KwaZulu-Natal; HIV; Primary; Acquired; Drug Resistance.

\section{Introduction}

According to the UNAIDS statistics (2012) sub-Saharan Africa has the highest numbers of adults and children living with HIV (22.5 million) and those newly infected with HIV (1.8 million) worldwide [1]. South Africa's epidemic remains the largest in the world with an estimated 6 million people living with HIV in 2011 [2]. KwaZulu-Natal (KZN) is the province with the highest HIV burden, with an HIV prevalence of $38 \%$ among women participating in ante-natal surveys [3]. However, since 2004 the rapid expansion of the availability of antiretroviral therapy (ART) in South Africa, has led to the decline in the annual HIV incidence among women 15-24 years old from 5.5 per 100 individuals in 2003-2005 to 2.2 in 2005-2008 [4]. The wide use of ART has been reported to be one of the main interventions responsible for decreasing the incidence of HIV-1 infection in rural KZN [5].

Antiretroviral therapy was implemented after the announcement of the Operational Plan for Comprehensive HIV and AIDS Care and Treatment for South Africa through the public health system with treatment regimens specified by the South African National adult and paediatric guidelines [6]. Currently, South Africa has the largest ART programme [7] with an estimated 1.79 million people on ART [8], the majority (85\%) through the public health sector, $4 \%$ through nongovernmental community treatment programmes and $11 \%$ through the private health sector. The ART roll-out has profoundly reduced AIDSrelated morbidity and mortality in resource poor settings $[9,10]$. There is evidence of an increase in adult life expectancy in South Africans since the initiation of ART [11,12].

KwaZulu-Natal and Gauteng provinces account for 56\% of all patients receiving or on ART in South Africa. An inevitable consequence of ART is drug resistance. Virological failure of ART regimens and accumulation of drug resistance mutations in adults and children in South Africa have been reported from several treatment programmes. We performed a comprehensive literature review of primary and acquired resistance in adults and children to both first- and second-line regimens in KZN. This was done to better understand temporal trends and possible transmission dynamics of drug resistance over a ten year period (2003-2013).

*Corresponding authors: Photini Kiepiela, HIV Prevention Research Unit, Medical Research Council, 123 Jan Hofmeyr Road, Westville 3630, Durban, South Africa, Tel: +27 312423656; Fax: +27 312423800; E-mail: pkiepiela@mrc.ac.za

Justen Manasa, Africa Centre for Health and Population Studies, College of Health Sciences, University of KwaZulu-Natal, Durban, South Africa, E-mail: jmanasa@gmail.com

Received February 17, 2014; Accepted April 15, 2014; Published April 25, 2014

Citation: Kiepiela P, Manasa J, Moosa MY, Moodley P, Gordon M, et al. (2014) HIV Drug Resistance Patterns at the Epicentre of the HIV-1 Epidemic in Kwazulu-Natal, South Africa 2003-2013. J AIDS Clin Res 5: 299. doi:10.4172/2155-6113.1000299

Copyright: ( 2014 Kiepiela P, et al. This is an open-access article distributed under the terms of the Creative Commons Attribution License, which permits unrestricted use, distribution, and reproduction in any medium, provided the original author and source are credited. 
Articles were retrieved from PubMed using the following key search terms: "HIV drug resistance and KwaZulu-Natal" (Figure 1). Permission was requested from the authors to include their published data in this report.

\section{Transmitted Drug Resistance (TDR)}

The surveillance of TDR is essential in a public health approach to ART. The levels and patterns of TDR can guide the selection of the first-line regimens and impact on post exposure prophylaxis policies. In resource constrained settings the World Health Organization (WHO) recommends focused surveillance for TDR in individuals likely to be recently infected [13]. A convenient population to sample for TDR is young ( $<25$ years) primigravida attending antenatal clinics (ANC) in areas where ART has been available for at least 3 years. Alternative estimates may be obtained from longitudinal studies of HIV seroconversion with estimated dates. In addition, WHO suggest using HIV threshold survey methods that allows the categorization of TDR as $<5 \%, 5-15 \%$ and $<15 \%$ [13]. A number of these surveys have been

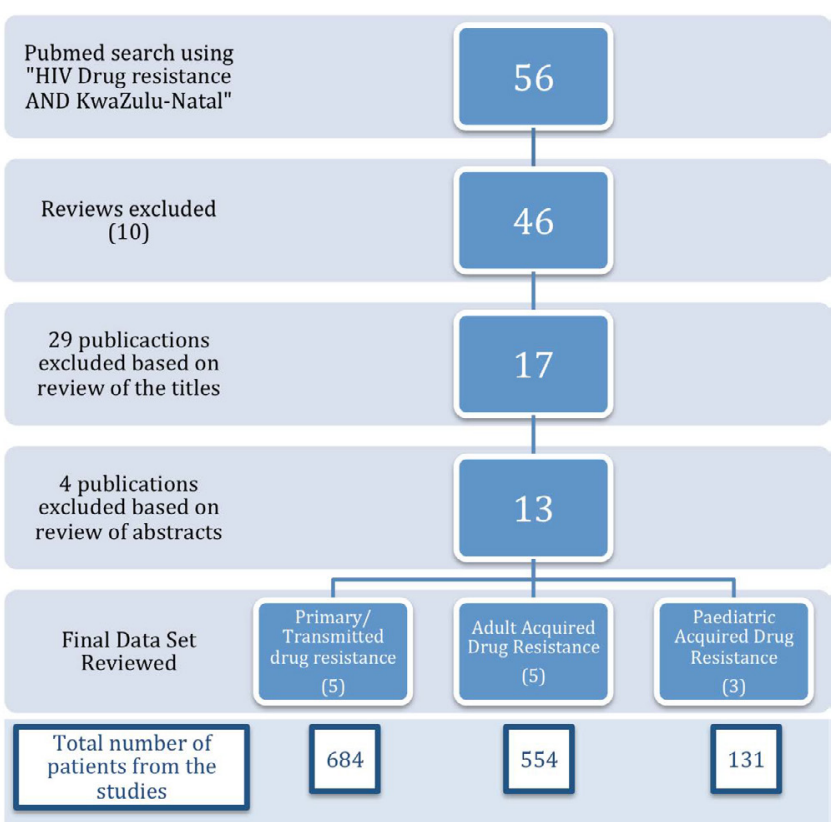

Figure 1: Pubmed search using the key words, "HIV drug resistance AND KwaZulu-Natal". The final analysis was based on 13 publications only. These studies reported drug resistance data from treatment naïve patients as well as adult and pediatric patients failing first line therapy. The treatment naïve patients studies reported data from a total of 684 patients while the adult and pediatric studies reported data from 554 and 131 patients respectively. performed in KZN $[14,15]$.

Furthermore, regular cross sectional studies in recent seroconverters and latently infected individuals has provided information on TDR [1618].

Table 1 summarizes the studies on TDR undertaken in KZN. The first study on drug resistance in treatment naïve patients from KZN was reported by Gordon et al. in 2003 prior to the "roll out" of the public antiretroviral programme [16]. They showed no evidence of TDR in 56 treatment naïve chronically infected patients. A report by Hunt et al. using WHO threshold surveys in KZN between 2005 and 2009 showed TDR levels increasing from $<5 \%$ to $5-15 \%$ [15]. One of 40 (2.5\%) samples genotyped had evidence of surveillance drug resistance mutations (SDRMs) [19] in 2005, whereas none of 34 samples genotyped in 2007, had evidence of TDR. However, 5/37 (13.5\%) and 3/47 (6.4\%) had SDRMs in 2008 and 2009 respectively [15]. The number of samples successfully genotyped in 2005 and 2008 were less than the recommended 47 when there is at least one SDRM. Thus the estimates of TDR for these two years could have been underestimated. Drug resistance mutations associated with NNRTI resistance were primarily responsible for the increase in TDR for all the years that had TDR levels greater than $5 \%$.

Another WHO threshold survey performed in 2009 detected SDRMs in only one sample out of 47 (2.1\%) genotyped [14]. This latter finding is supported by Manasa et al. who did not find any SDRMs in72 samples from recently infected patients identified in 2010 through a longitudinal population based HIV surveillance programme from rural KZN [17].

The most recent report from a cross sectional study undertaken in semi-rural and urban sites in the greater Durban area of KZN, on women being screened for an HIV prevention trial between 2010 and 2011 found that $26 / 352$ (7.4\%) women had at least one SDRM. Twenty of the 26 had resistance to a single class, NNRTI, NRTI or PI. The remaining six had dual class resistance, five (NNRTI + NRTI) and one $($ NNRTI + PI) resistance. Twenty three of the 26 patients had NNRTI resistance, 19 had the K103N mutation [18].

Most of the studies above show that TDR is still low $(<5 \%)$ in KZN, similar to other provinces in South Africa [15,20-24]. However, the 2008 and 2009 data by Hunt et al. suggest that TDR might be increasing to intermediate levels predominantly due to NNRTI resistance. This trend is similar to observations from west and central Africa as well as Zambia, who have had more experience with ART [24-27]. NNRTI resistance mutations are stable and have little impact on viral fitness, thus they tend to persist for a longer time than mutations to other drug classes [28]. This and the ease with which they are selected under

\begin{tabular}{|c|c|c|c|c|c|c|c|}
\hline Study Period & Patient Population & N & Any mutation (\%) & NNRTI (\%) & NRTI (\%) & PI (\%) & Reference \\
\hline $\mathbf{2 0 1 1}$ & Treatment naïve women & 351 & 7.4 & 5.7 & 2.0 & 0.6 & Parikh et al. [13] \\
\hline $\mathbf{2 0 1 0}$ & HIV surveillance & 72 & 0.0 & 0.0 & 0.0 & 0.0 & Manasa et al. [17] \\
\hline $\mathbf{2 0 0 9}$ & ANC Survey & 47 & $<5.0$ & $<5.0(2.1)$ & $<5.0$ & $<5.0$ & Parboosing et al. [14] \\
\hline $\mathbf{2 0 0 9}$ & ANC Survey & 47 & $5-15$ & $5-15$ & $<5.0$ & $<5.0$ & Hunt et al. [15] \\
\hline $\mathbf{2 0 0 \boldsymbol { 8 } ^ { * }}$ & ANC Survey & 37 & 13.5 & 8.1 & 5.4 & 2.7 & Hunt et al. [15] \\
\hline $\mathbf{2 0 0 7}$ & ANC Survey & 34 & $<5.0$ & $<5.0$ & $<5.0$ & $<5.0$ & Hunt et al. [15] \\
\hline $\mathbf{2 0 0 5}$ & ANC Survey & 40 & 2.5 & 2.5 & ND & ND & Hunt et al. [15] \\
\hline $\mathbf{2 0 0 3}$ & Treatment naïve adults & 56 & $<5.0$ & $<5.0(2.1)$ & $<5.0$ & $<5.0$ & Gordon et al. [16] \\
\hline
\end{tabular}

* The threshold level could not be determined because of insufficient numbers of samples genotyped.

$\mathrm{N}$ - number of patients genotyped; NNRTI - Non-nucleoside reverse transcriptase inhibitor; ND - not determined; NRTI - nucleoside reverse transcriptase inhibitor; PI protease inhibitor; 
suboptimal therapy as well as the wide use of first-line agents might be the contributory factors towards the disproportionately higher levels of NNRTI TDR relative to NRTI TDR.

There are several limitations to the TDR data reviewed. Most studies had a small sample size; surveyed limited regions; had short duration of follow up; were retrospective and lacked verification of prior ART exposure which may have inflated the TDR levels by including patients with previous ART exposure.

\section{Acquired Resistance Mutations After Virologic Failure to First-Line Regimens in Adults in KZN}

From inception in 2004, the South African national treatment programme has used standardized first-line and second-line regimens. The South African national adult treatment guidelines recommended a first-line regimen consisting of two NRTIs (stavudine (d4T) + lamivudine (3TC)) combined with one NNRTI (efavirenz (EFV) or nevirapine (NVP)) [6]. Stavudine was replaced by tenofovir (TDF) in 2010 due to toxicity [29]. Unlike most resource-constrained settings, South Africa recommended 6 monthly viral load monitoring in its guidelines, however drug resistance testing for patients failing therapy was not recommended. Patients with confirmed virological failure were switched to a standardized second-line regimen consisting of two NRTIs and a boosted PI. Studies in patients failing first-line therapy are not only informative on the performance of ART programmes but also on the appropriateness of the standardized second-line treatment regimens.

Table 2 summarizes the five published studies reporting drug resistance mutations in adult patients failing first-line regimens in KZN [30-34]. All but one recruited participants from urban hospital- based clinics. The two urban hospital sites used were: the Sinikithemba Outpatient HIV/AIDS clinic, McCord Hospital and iThemba clinic, St Mary's Hospital in Durban [30-33]. All studies showed similar results, with drug resistance in $>80 \%$ of patients failing first-line ART. Only two studies reported on their virologic failure rates, which ranged from 6 to $10 \%[33,34]$.

All studies reported at least one drug resistance mutation in over 80 percent of patients failing first-line treatment. Murphy et al. reported on patients failing therapy from both urban sites between 2004 and 2006. They showed that $86.5 \%$ of the patients failing therapy had one or more drug resistance mutations. Five percent of the patients had the K65R mutation [31]. In 2005 and 2006 Marconi et al. also recruited patients from the same two clinics and found similar levels of drug resistance. One or more drug resistance mutations were detected in $83.5 \%$. More than half of these harboured resistance to two drug classes. Prevalence of thymidine analogue mutations (TAMs) was low. The most frequent mutations detected were M184V/I and K103N [30].

Singh et al. in 2011 detected at least one resistance mutation in 95\% of patients failing ART: $91 \%$ had evidence of resistance to both NRTI and NNRTIs. The only reported PI mutation; T74S is a subtype C polymorphism [32].

Another study also done at the Sinikithemba clinic between 2010 and 2011 genotyped patients failing a new first-line regimen of TDF $+3 T C+$ EFV/ NVP that had been introduced in 2010 [33]. The study followed up 585 patients over a period of approximately six months. The reported virological failure rate was $6 \%$ at median follow up of 5.7 months. Approximately $70 \%$ of the virologic failures had the K65R mutation with few additional NRTI mutations. There were fewer M184V mutations and TAMs compared to other reports from KZN or

\begin{tabular}{|c|c|c|c|c|c|c|c|c|c|c|c|c|}
\hline Study Period & Site & $\begin{array}{l}\text { Criteria for } \\
\text { failure }\end{array}$ & $\mathbf{N}$ & $\begin{array}{l}\text { Median } \\
\text { Duration } \\
\text { of ART } \\
\text { (months) }\end{array}$ & ART Regimen (\%) & $\begin{array}{l}\geq 1 \text { DRM } \\
(\%)\end{array}$ & $\begin{array}{l}\text { NNRTI } \\
(\%)\end{array}$ & $\begin{array}{l}\text { M184V } \\
(\%)\end{array}$ & $\begin{array}{l}\text { Any TAM } \\
(\%)\end{array}$ & $\begin{array}{l}\text { TAM } \geq 3 \\
(\%)\end{array}$ & $\begin{array}{l}\text { K65R } \\
(\%)\end{array}$ & Ref \\
\hline $\begin{array}{l}\text { Dec } 2010 \text { - Mar } \\
2012\end{array}$ & $\begin{array}{l}\text { Hlabisa } \\
\text { (17 rural clinics) }\end{array}$ & $1 \times V L>1000$ & 222 & 42 & $\begin{array}{l}\text { d4T/3TC/EFV (51) } \\
\text { d4T/3TC/NVP (24) } \\
\text { AZT/3TC/EFV (8) } \\
\text { TDF/3TC/EFV (11) } \\
\text { Other (6) }\end{array}$ & 86.0 & 83.0 & 78.0 & 40.0 & 18.0 & 6.0 & $\begin{array}{l}\text { Manasa et al. } \\
{[34]}\end{array}$ \\
\hline $\begin{array}{l}\text { Sep } 2010 \text { to Mar } \\
2011\end{array}$ & Urban clinic & $1 \times V L>1000$ & 33 & 5.7 & TDF/3TC/EFV (89) & $>97.0$ & 97.0 & 27.3 & 15.2 & NR & 70.0 & $\begin{array}{l}\text { Sunpath et } \\
\text { al. [33] }\end{array}$ \\
\hline NR & $\begin{array}{l}\text { Durban } \\
\text { (urban hospital) }\end{array}$ & $1 \times V L>5000$ & 43 & 29 & $\begin{array}{l}\text { d4T/3TC/EFV (51) } \\
\text { AZT/3TC/EFV (29) } \\
\text { AZT/3TC/NVP (9) } \\
\text { Other (10) }\end{array}$ & 95.0 & 95.0 & 87.0 & 55.0 & NR & NR & $\begin{array}{l}\text { Singh et al. } \\
\text { [32] }\end{array}$ \\
\hline $\begin{array}{l}\text { Aug } 2004 \text { to Aug } \\
2006\end{array}$ & Urban Clinics & $1 \times V L>1000$ & 141 & NR & $\begin{array}{l}\text { D4T/3TC/EFV (43) } \\
\text { D4T/3TC/NVP (6) } \\
\text { AZT/3TC/EFV (27) } \\
\text { AZT/3TC/NVP (12) } \\
\text { OTHER (11) }\end{array}$ & 86.5 & NR & NR & NR & NR & 5.0 & $\begin{array}{l}\text { Murphy et al. } \\
\text { [31] }\end{array}$ \\
\hline $\begin{array}{l}\text { Jan } 2005 \text { - Aug } \\
2006\end{array}$ & $\begin{array}{l}\text { Durban } \\
\text { (two urban hospitals) }\end{array}$ & $1 \times V L>1000$ & 115 & 10.8 & $\begin{array}{l}\mathrm{d} 4 \mathrm{~T} / 3 \mathrm{TC} / \mathrm{EFV}(49) \mathrm{d} 4 \mathrm{~T} / 3 \mathrm{TC} / \\
\text { NVP (5) } \\
\text { AZT/3TC/EFV (26) } \\
\text { AZT/3TC/NVP (11) } \\
\text { Other (8) }\end{array}$ & 83.5 & 78.3 & 64.3 & 32.2 & 13.0 & 2.6 & $\begin{array}{l}\text { Marconi et al. } \\
{[30]}\end{array}$ \\
\hline
\end{tabular}

ART, antiretroviral therapy; N, number of patients genotyped; DRM, drug resistance mutation; TAM, thymidine analogue mutation; VL, viral load; NR, Not reported; NA, Not applicable; Ref- Reference.

Table 2: Summary of acquired drug resistance studies in adults treated with first-line antiretroviral therapy in KwaZulu-Natal (KZN), South Africa. 
the rest of South Africa [30-32,34]. The early development of K65R in the patients included in this study might have been responsible for the low levels of TAMs due to the reported antagonism between TAMs and the K65R mutation [35,36]. Only 33 patients were genotyped in this first study of resistance after failure of a TDF based first-line regimen. Larger studies with more power are needed to have a clearer understanding of the rate of emergence and patterns of drug resistance in patients failing the new standard first-line regimen [33]. Another report [37], showed that there were no significant differences in virological control between Zidovudine (AZT), d4T or TDF first-line regimens. The preferential selection of K65R in patients on TDF based first-line regimen has been attributed to a more rapid in vivo selection of the K65R mutation in clade $\mathrm{C}$ virus [38].

However, TDF based regimens were associated with less single drug substitution (mostly associated with toxicity) as well as mortality when compared to the regimens based on either AZT or d4T [37].

The most recent report on acquired drug resistance on firstline therapy failure was from Manasa et al. Unlike previous studies this report was from a rural decentralized treatment programme in northern KZN [34]. Here patients were recruited from 17 primary health care clinics in the Hlabisa sub-district between 2010 and 2012. They reported a virologic failure rate of $10 \%$ over the two year study period. This report only included patients receiving d4T/ AZT based first-line regimen. One or more drug resistance mutations were found in $86 \%$ of the patients. One or more TAMs were detected in $40 \%$ of the patients while $18 \%$ had three or more TAMs. The K65R mutation was detected in $6 \%$ of the patients. In addition to the mutations, the authors reported on the total genotypic susceptibility scores (GSS) of the viral isolates to the recommended second-line regimen. Based on the GSS approximately $15 \%$ of the patients harboured viruses with resistance levels that could potentially compromise the effectiveness of the standard second-line regimen [34].

The average time on failing regimens among the patients from rural KZN was 26 months. There is limited data from other studies on the time patients spent on failing regimens, however it is anticipated that it will be significantly lower for patients being managed through hospital based programmes in urban centres. Prolonged periods on failing regimens are associated with accumulation of high-level resistance, which may compromise second-line treatment options in both children and adults. This study highlighted that: as the treatment programme expands, there is a need to adhere to treatment and monitoring guidelines more closely in order to identify patients failing therapy early and act quickly to provide the appropriate clinical management. The study also seems to highlight the importance of introducing drug resistance testing for those participants failing first-line therapy, so that they are put on the most effective second-line therapy available, especially if remaining on a failing first-line regimen for prolonged periods of time compromises second-line therapy.

Most of the above reports are similar to reports from other parts of South Africa as well as the rest of the continent [39-44]. Failure of first-line drug regimens in adults was associated with at least one mutation from either the NRTI or NNRTI, with significant proportions harbouring drug resistance mutations to both classes. The most common drug resistance mutations were M184V and K103N while 15 to $55 \%$ of the patients had evidence of one or more TAMs.

There are no published reports on drug resistance mutations on second-line ART failure in KZN.

\section{Acquired Resistance Mutations After Virologic Failure to First-Line Regimens in Children in KZN}

There are only three reports of paediatric HIV-1 drug resistance to first-line regimens in KZN as summarized in Table 3. One from the Sinikithemba paediatric HIV-1 cohort at McCord Hospital, Durban, South Africa [45]; the second from the King Edward VIII hospital, Durban [46] and the most recent study from rural clinics in the Hlabisa sub-district of rural KZN [47]. The study from the Sinikithemba Clinic was a case study describing resistance in a child less than 3 years coinfected with $M$ tuberculosis. The child had the NRTI mutations K65R, and D67N as well as the PI mutations, M46I, I54V and V82A [45].

Green et al. in 2012 found that in children failing HAART, 85.4\% had $>1$ drug resistance mutation to one drug class and $80.5 \%$ to 2 drug classes. The most common NRTI mutations were M184V (70.7\%), K219E (43.9\%), K70R (36.6\%) and D67N (34.1\%). The K65R resistance mutation was found in $7.3 \%$ of children failing HAART. The most common NNRTI mutations were V106M (41.5\%) and K103N (39\%), $58.5 \%$ had $>1$ TAM and $39.0 \%$ had $\geq 3$ TAMs. Although $14.6 \%$ of 41 children had mutations from the TAM1 (M41L, L210W, T215Y) and TAM2 (D67N, K70R, T215F, K219Q/E) pathways, the latter predominated $16(39.0 \%)$ over the former $2(4.9 \%)$ [46]. Fortunately TAM2 pathway mutations are associated with lesser virologic fitness compared to TAM1 mutations. In addition, they are associated with lesser cross resistance such that TDF remains active in the presence of TAM2 mutation [48].

The study from the Hlabisa sub district also showed similar levels of resistance. One or more drug resistance mutations were detected in $91 \%$ of the patients failing therapy. The most common mutation was the M184V mutation. Resistance to the NNRTIs was detected in $71.9 \%$ of the patients. Any TAM and/or more than three TAMs were detected in $23.4 \%$ and $5.5 \%$ of the patients respectively [47]. The accumulation of

\begin{tabular}{|c|c|c|c|c|c|c|c|c|c|c|c|c|}
\hline Study Period & Site & Criteria for failure & $\mathbf{N}$ & $\begin{array}{l}\text { Median Duration } \\
\text { of ART (months) }\end{array}$ & ART Regimen (\%) & $\begin{array}{l}\geq 1 \text { DRM } \\
(\%)\end{array}$ & $\begin{array}{l}\text { NNRTI } \\
\text { (\%) }\end{array}$ & $\begin{array}{l}\text { M184V } \\
(\%)\end{array}$ & $\begin{array}{l}\text { TAM } \\
(\%)\end{array}$ & $\begin{array}{l}\text { TAM } \geq 3 \\
(\%)\end{array}$ & $\begin{array}{l}\text { K65R } \\
(\%)\end{array}$ & Ref \\
\hline $\begin{array}{l}\text { Aug 2011- Dec } \\
2012\end{array}$ & Rural clinics & $1 \times V L>1000$ & 89 & 39.6 & $\begin{array}{l}\text { d4T/3TC/EFV (72) } \\
\text { d4T/3TC/LPVr (14) } \\
\text { ABC/3TC/EFV (9) } \\
\text { Other (6) }\end{array}$ & 91.0 & 71.9 & 78.7 & 23.4 & 5.5 & 5.6 & $\begin{array}{l}\text { Pillay et al. } \\
\text { [47] }\end{array}$ \\
\hline $\begin{array}{l}\text { Aug } 2008 \text { to Jan } \\
2010\end{array}$ & Urban Hospital & $1 \times V L>1000$ & 41 & 28.6 & $\begin{array}{l}\text { d4T/3TC/EFV (61) } \\
\text { d4T/3TC/LPVr (15) } \\
\text { AZT/3TC/NVP (7) } \\
\text { Other (10) }\end{array}$ & 85.4 & 78.0 & 70.7 & 58.5 & 39.0 & 7.3 & $\begin{array}{l}\text { Green et al. } \\
{[46]}\end{array}$ \\
\hline 2009 & Urban Clinic & $1 \times V L>1000$ & 1 & $\sim 22$ & $\begin{array}{l}\text { D4T/3TC/RTV } \\
\text { AZT/3TC/LPVr }\end{array}$ & NA & NA & NA & NA & NA & NA & $\begin{array}{l}\text { Murphy et al. } \\
\text { [45] }\end{array}$ \\
\hline
\end{tabular}

ART, antiretroviral therapy; N, number of patients genotyped; DRM, drug resistance mutation; TAM, thymidine analogue mutation; VL, viral load; NR, Not reported; NA, Not applicable; Ref, Reference

Table 3: Summary of acquired drug resistance studies in children treated with first-line antiretroviral therapy in KwaZulu-Natal, South Africa. 
TAMs is likely due to the duration on a failing regimen, underscoring the importance of early switching using viral load estimation to monitor the response to ART. Interestingly, only $1 / 17$ patients on PIbased regimen had PI drug resistance mutation. This likely reflects poor adherence to the paediatric lopinavir/ritonavir liquid formulation.

\section{Conclusion}

The TDR level in KZN, the province considered to be at the epicentre of the HIV-1 epidemic, is low to medium with a dominance of NNRTI resistance mutations. Further studies to evaluate the impact of the increasing treatment coverage on the levels of TDR are needed.

The patterns and levels of acquired resistance were very similar among patients failing comparable regimens in KZN and did not differ from other cohorts in South Africa and the rest of the continent. However, there remains a need to assess the failure rates and resistance patterns of patients failing the new TDF based first-line regimen.

There is a need to seriously consider integrating drug resistance testing in the continuum of care, particularly in light of a study that has shown that the cost of genotypic drug resistance testing is cost saving for patients failing second-line therapy and cost neutral for patients failing first-line therapy [49].

Genotyping patients failing second-line therapy is recommended by the South African National Treatment Guideline. The PASER study showed that about one third of adults failing first-line regimens have wild type genotypes [50]. In the absence of genotypic resistance testing these patients have poorer outcomes when switched to second-line regimens without accurately assessing antiretroviral adherence.

The appropriate use of HIV drug-resistance testing together with improved quality of care in HIV programmes will ultimately result in the long term reduction of the spread and emergence of drug resistance in low income settings [51].

\section{Acknowledgements}

We wish to thank Drs R. Parboosing, R. Murphy, V. Marconi and G. Hunt for permission to include their data in this manuscript. Our sincere thanks to Prof $D$ Katzenstein for reviewing the manuscript and his valuable input.

\section{References}

1. UNAIDS (2012) Global report. UNAIDS report on the global AIDS epldemic. Geneva, UNAIDS.

2. UNAIDS (2012) UNAIDS World AIDS Day Report.

3. Department of Health RoSA (2012) The 2011 National Antenatal Sentinel HIV \& Syphilis Prevalence Survey in South Africa. In: Health Do, editor.

4. Rehle TM, Hallett TB, Shisana O, Pillay-van Wyk V, Zuma K, et al. (2010) A decline in new HIV infections in South Africa: estimating HIV incidence from three national HIV surveys in 2002, 2005 and 2008. PLoS One 5: e11094.

5. Tanser F, Bärnighausen T, Grapsa E, Zaidi J, Newell ML (2013) High coverage of ART associated with decline in risk of HIV acquisition in rural KwaZulu-Natal, South Africa. Science 339: 966-971.

6. Department of Health RoSA (2004) Clinical guideline for the management of HIV and AIDS in adults and adolescents In: Health Do, editor.

7. UNAIDS (2012) HIV treatment now reaching more than 6 million people in subSaharan Africa.

8. Johnson FL (2012) Access to Antiretroviral Treatment in South Africa, 2004 2011. The South African Journal of HIV Medicine 13: 6.

9. Severe P, Leger P, Charles M, Noel F, Bonhomme G, et al. (2005) Antiretroviral therapy in a thousand patients with AIDS in Haiti. N Engl J Med 353: 23252334.

10. Egger M, Boulle A (2008) Population effect of scaling up ART in resource-poor settings. Lancet 371: 1558-1559.
11. Bor J, Herbst AJ, Newell ML, Bärnighausen T (2013) Increases in adult life expectancy in rural South Africa: valuing the scale-up of HIV treatment. Science 339: 961-965.

12. Johnson LF, Mossong J, Dorrington RE, Schomaker M, Hoffmann CJ, et al. (2013) Life expectancies of South African adults starting antiretroviral treatment collaborative analysis of cohort studies. PLoS Med 10: e1001418.

13. Bennett DE, Myatt M, Bertagnolio S, Sutherland D, Gilks CF (2008) Recommendations for surveillance of transmitted HIV drug resistance in countries scaling up antiretroviral treatment. Antivir Ther 13 Suppl 2: 25-36.

14. Parboosing R, Naidoo A, Gordon M, Taylor M, Vella V (2011) Resistance to antiretroviral drugs in newly diagnosed, young treatment-naïve HIV-positive pregnant women in the province of KwaZulu-Natal, South Africa. J Med Virol 83: 1508-1513.

15. Hunt GM, Ledwaba J, Basson AE, Moyes J, Cohen C, et al. (2012) Surveillance of transmitted HIV-1 drug resistance in Gauteng and KwaZulu-Natal Provinces South Africa, 2005-2009. Clin Infect Dis 54 Suppl 4: S334-338.

16. Gordon M, De Oliveira T, Bishop K, Coovadia HM, Madurai L, et al. (2003) Molecular characteristics of human immunodeficiency virus type 1 subtype C viruses from KwaZulu-Natal, South Africa: implications for vaccine and antiretroviral control strategies. J Virol 77: 2587-2599.

17. Manasa J, Katzenstein D, Cassol S, Newell ML, de Oliveira T; Southern Africa Treatment And Resistance Network (SATuRN) (2012) Primary drug resistance in South Africa: data from 10 years of surveys. AIDS Res Hum Retroviruses 28: $558-565$.

18. Parikh UM, Kiepiela P, Ganesh S, Gomez K, Horn S, et al. (2013) Prevalence of HIV-1 drug resistance among women screening for HIV prevention trials in KwaZulu-Natal, South Africa (MTN-009). PLoS One 8: e59787.

19. Shafer RW, Rhee SY, Bennett DE (2008) Consensus drug resistance mutations for epidemiological surveillance: basic principles and potential controversies. Antivir Ther 13 Suppl 2: 59-68.

20. Pillay V, Ledwaba J, Hunt G, Rakgotho M, Singh B, et al. (2008) Antiretrovira drug resistance surveillance among drug-naive HIV-1-infected individuals in Gauteng Province, South Africa in 2002 and 2004. Antivir Ther 13 Suppl 2: 101-107.

21. Iweriebor BC, Mavhandu LG, Masebe T, Rekosh D, Hammarskjold ML, et al. (2012) Molecular epidemiology of HIV in two highly endemic areas of northeastern South Africa. Arch Virol 157: 455-465.

22. Nwobegahay J, Bessong P, Masebe T, Mavhandu L, Manhaeve C, et al. (2011) Prevalence of drug-resistant mutations in newly diagnosed drug-naïve HIV1-infected individuals in a treatment site in the Waterberg district, Limpopo province. S Afr Med J 101: 335-337.

23. Nwobegahay J, Selabe G, Ndjeka NO, Manhaeve C, Bessong PO (2012) Low prevalence of transmitted genetic drug resistance in a cohort of HIV infected naive patients entering antiretroviral treatment programs at two sites in northern South Africa. J Med Virol 84: 1839-1843.

24. Hamers RL, Wallis CL, Kityo C, Siwale M, Mandaliya K, et al. (2011) HIV-1 drug resistance in antiretroviral-naive individuals in sub-Saharan Africa after rollout of antiretroviral therapy: a multicentre observational study. Lancet Infect Dis 11: 750-759.

25. Price MA, Wallis CL, Lakhi S, Karita E, Kamali A, et al. (2011) Transmitted HIV type 1 drug resistance among individuals with recent HIV infection in East and Southern Africa. AIDS Res Hum Retroviruses 27: 5-12.

26. Ndembi N, Hamers RL, Sigaloff KC, Lyagoba F, Magambo B, et al. (2011) Transmitted antiretroviral drug resistance among newly HIV-1 diagnosed young individuals in Kampala. AIDS 25: 905-910.

27. Aghokeng AF, Kouanfack C, Laurent C, Ebong E, Atem-Tambe A, et al. (2011) Scale-up of antiretroviral treatment in sub-Saharan Africa is accompanied by increasing HIV-1 drug resistance mutations in drug-naive patients. AIDS 25 : 2183-2188.

28. Coffin JM (1995) HIV population dynamics in vivo: implications for genetic variation, pathogenesis, and therapy. Science 267: 483-489.

29. Department of Health RoSA (2010) Clinical guideline for the management of HIV and AIDS in adults and adolescents In: Health Do, editor

30. Marconi VC, Sunpath H, Lu Z, Gordon M, Koranteng-Apeagyei K, et al. (2008) Prevalence of HIV-1 drug resistance after failure of a first highly active 
Citation: Kiepiela P, Manasa J, Moosa MY, Moodley P, Gordon M, et al. (2014) HIV Drug Resistance Patterns at the Epicentre of the HIV-1 Epidemic in Kwazulu-Natal, South Africa 2003-2013. J AIDS Clin Res 5: 299. doi:10.4172/2155-6113.1000299

antiretroviral therapy regimen in KwaZulu Natal, South Africa. Clin Infect Dis 46: $1589-1597$

31. Murphy RA, Sunpath H, Lu Z, Chelin N, Losina E, et al. (2010) Outcomes after virologic failure of first-line ART in South Africa. AIDS 24: 1007-1012.

32. Singh A, Sunpath H, Green TN, Padayachi N, Hiramen K, et al. (2011) Drug resistance and viral tropism in HIV-1 subtype C-infected patients in KwaZuluNatal, South Africa: implications for future treatment options. J Acquir Immune Defic Syndr 58: 233-240.

33. Sunpath H, Wu B, Gordon M, Hampton J, Johnson B, et al. (2012) High rate of K65R for antiretroviral therapy-naive patients with subtype $\mathrm{C}$ HIV infection failing a tenofovir-containing first-line regimen. AIDS 26: 1679-1684.

34. Manasa J, Lessells RJ, Skingsley A, Naidu KK, Newell ML, et al. (2013) Highlevels of acquired drug resistance in adult patients failing first-line antiretroviral therapy in a rural HIV treatment programme in KwaZulu-Natal, South Africa. PLoS One 8: e72152.

35. Parikh UM, Bacheler L, Koontz D, Mellors JW (2006) The K65R mutation in human immunodeficiency virus type 1 reverse transcriptase exhibits bidirectional phenotypic antagonism with thymidine analog mutations. J Virol 80: 4971-4977.

36. Parikh UM, Barnas DC, Faruki H, Mellors JW (2006) Antagonism between the $\mathrm{HIV}-1$ reverse-transcriptase mutation $\mathrm{K} 65 \mathrm{R}$ and thymidine-analogue mutations at the genomic level. J Infect Dis 194: 651-660.

37. Velen K, Lewis JJ, Charalambous S, Grant AD, Churchyard GJ, et al (2013) Comparison of tenofovir, zidovudine, or stavudine as part of first-line antiretroviral therapy in a resource-limited-setting: a cohort study. PLoS One 8: e64459.

38. Brenner BG, Oliveira M, Doualla-Bell F, Moisi DD, Ntemgwa M, et al. (2006) HIV-1 subtype $C$ viruses rapidly develop K65R resistance to tenofovir in cell culture. AIDS 20: F9-13.

39. Barth RE, Wensing AM, Tempelman HA, Moraba R, Schuurman R, et al (2008) Rapid accumulation of nonnucleoside reverse transcriptase inhibitorassociated resistance: evidence of transmitted resistance in rural South Africa. AIDS 22: 2210-2212.

40. Orrell C, Walensky RP, Losina E, Pitt J, Freedberg KA, et al. (2009) HIV type1 clade $C$ resistance genotypes in treatment-naive patients and after first virological failure in a large community antiretroviral therapy programme. Antivir Ther 14: 523-531.

41. Hoffmann CJ, Charalambous S, Sim J, Ledwaba J, Schwikkard G, et al. (2009)
Viremia, resuppression, and time to resistance in human immunodeficiency virus (HIV) subtype $\mathrm{C}$ during first-line antiretroviral therapy in South Africa. Clin Infect Dis 49: 1928-1935.

42. Wallis CL, Mellors JW, Venter WD, Sanne I, Stevens W (2010) Varied patterns of HIV-1 drug resistance on failing first-line antiretroviral therapy in South Africa. J Acquir Immune Defic Syndr 53: 480-484.

43. El-Khatib Z, Ekstrom AM, Ledwaba J, Mohapi L, Laher F, et al. (2010) Viremia and drug resistance among HIV-1 patients on antiretroviral treatment: a crosssectional study in Soweto, South Africa. AIDS 24: 1679-1687.

44. Sigaloff KC, Ramatsebe T, Viana R, de Wit TF, Wallis CL, et al. (2012) Accumulation of HIV drug resistance mutations in patients failing first-line antiretroviral treatment in South Africa. AIDS Res Hum Retroviruses 28: 171 175.

45. Murphy RA, France H, Sunpath H, Gordon ML, Marconi VC, et al. (2009) Development of dual-class antiretroviral drug resistance in a child coinfected with HIV and tuberculosis: a case report from KwaZulu-Natal, South Africa. $J$ Trop Pediatr 55: 60-62.

46. Green TN, Archary M, Gordon ML, Padayachi N, Lie Y, et al. (2012) Drug resistance and coreceptor usage in HIV type 1 subtype C-infected children initiating or failing highly active antiretroviral therapy in South Africa. AIDS Res Hum Retroviruses 28: 324-332.

47. Pillay S, Bland R, Lessells R, Manasa J, de Oliveira T, et al. (2013) Drug resistance in children with virological failure on first-line antiretroviral therapy: rural KwaZulu-Natal, South Africa. Paed Infect Dis J. In review.

48. Cozzi-Lepri A, Ruiz L, Loveday C, Phillips AN, Clotet B, et al. (2005) Thymidine analogue mutation profiles: factors associated with acquiring specific profiles and their impact on the virological response to therapy. Antivir Ther 10: 791802.

49. Rosen S, Long L, Sanne I, Stevens WS, Fox MP (2011) The net cost of incorporating resistance testing into HIVIAIDS treatment in South Africa: Markov model with primary data. J Int AIDS Soc 14: 24.

50. Hamers RL, Sigaloff KC, Wensing AM, Wallis CL, Kityo C, et al. (2012) Patterns of HIV-1 drug resistance after first-line antiretroviral therapy (ART) failure in 6 sub-Saharan African countries: implications for second-line ART strategies. Clin Infect Dis 54: 1660-1669.

51. Lessells RJ, Avalos A, de Oliveira T (2013) Implementing HIV-1 genotypic resistance testing in antiretroviral therapy programs in africa: needs opportunities, and challenges. AIDS Rev 15: 221-229. 